PSYCHOMETRIKA-VOL. 47 , NO. 4.

DECEMBER, 1982

ERRATUM

\title{
ERRATUM FOR \\ A COMPARISON OF SEVERAL $k$ SAMPLE TESTS FOR ORDERED ALTERNATIVES IN COMPLETELY RANDOMIZED DESIGNS
}

\author{
Mark L. Berenson \\ BARUCH COLLEGE, CUNY
}

Due to a printer's error, the columns of Table 1 of Berenson [1982] were misaligned. The correct version of the Table is given on the pages that follow. (Ed.) 


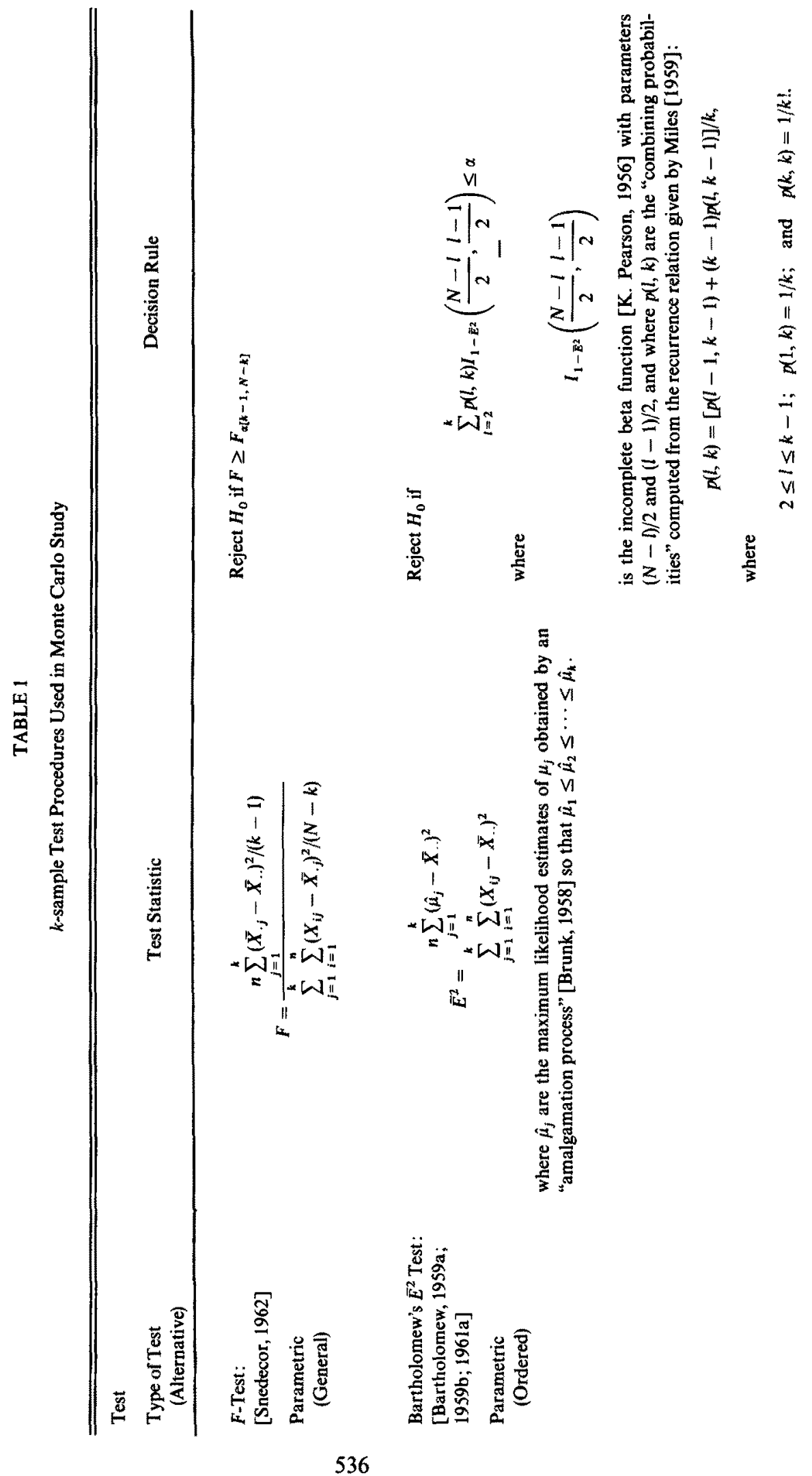



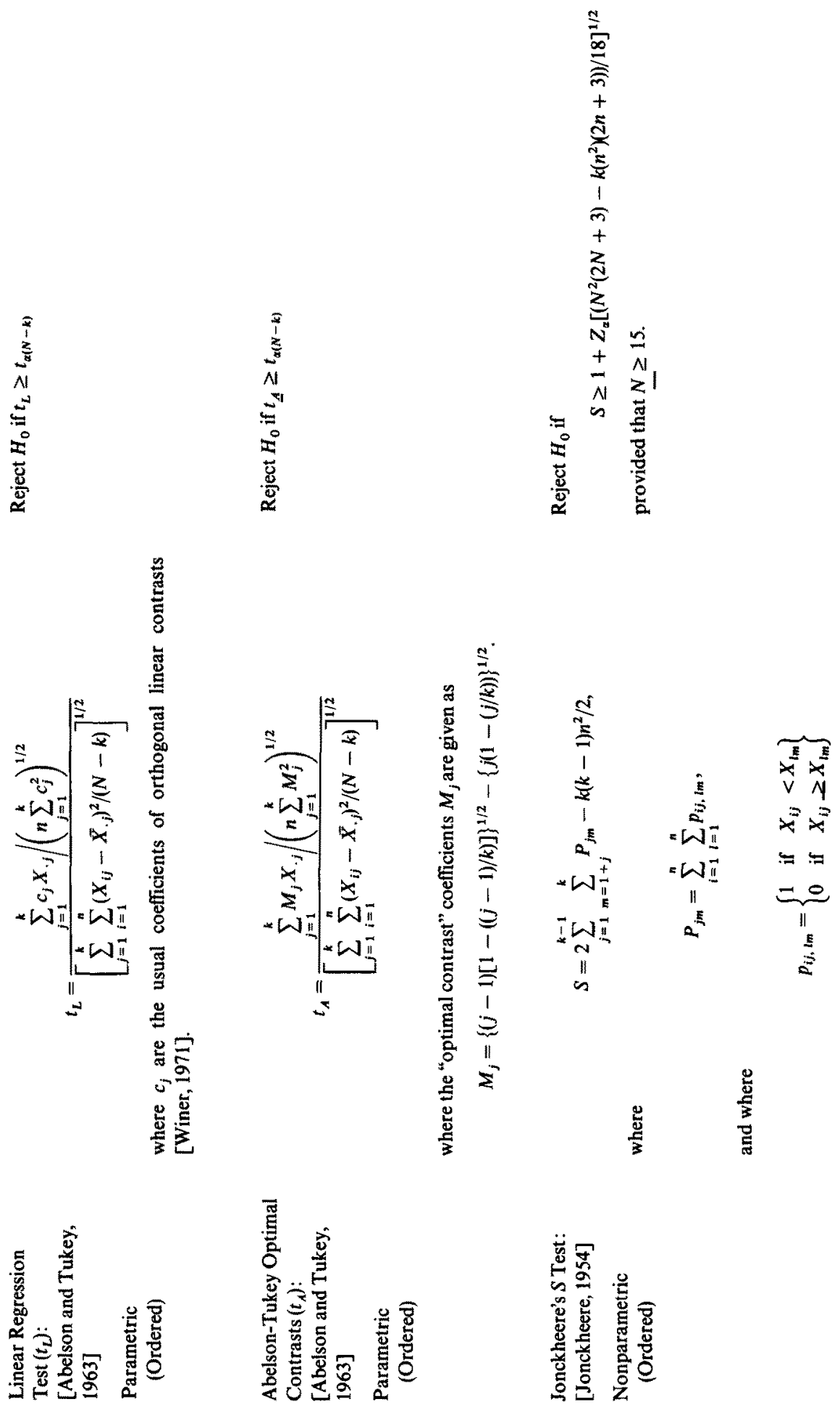


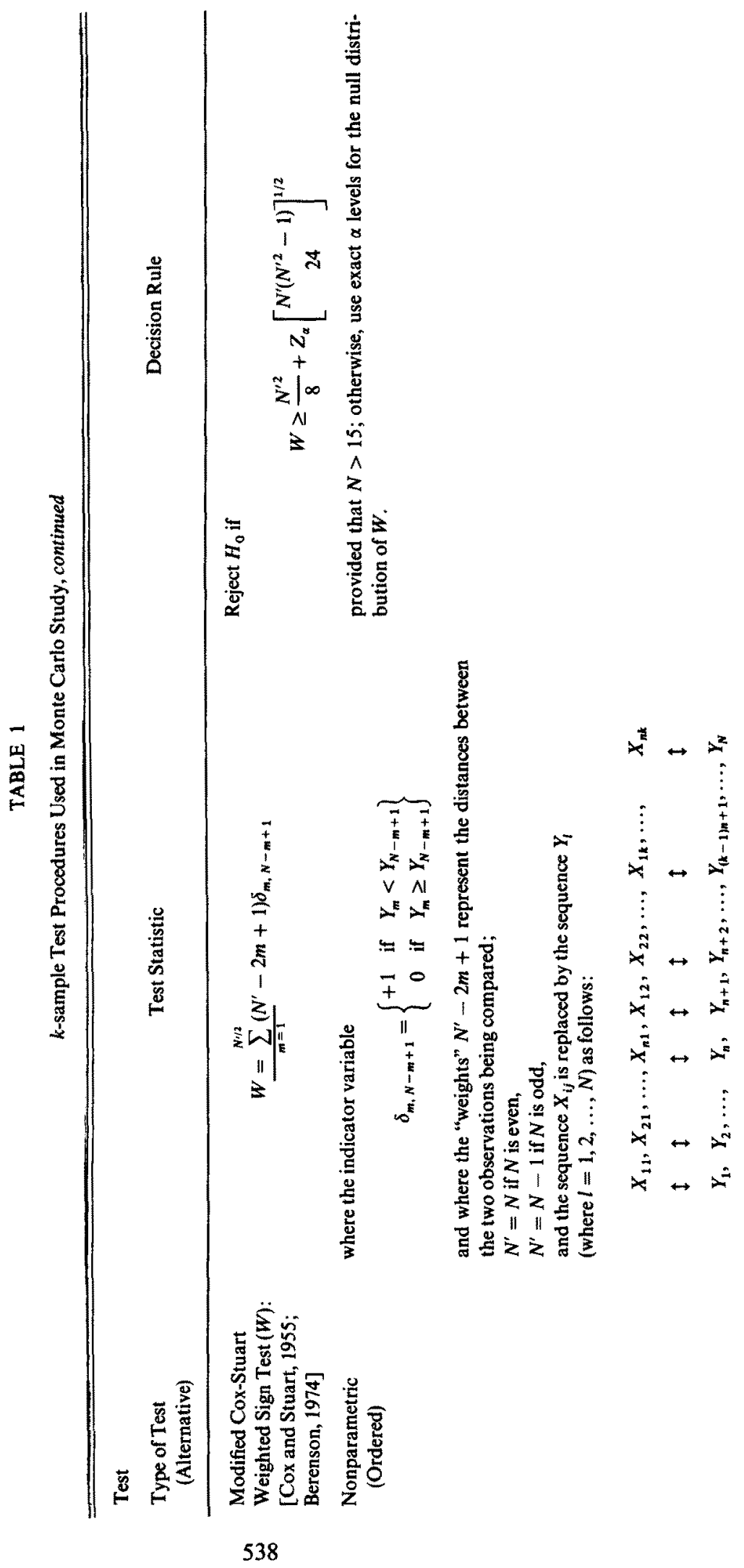



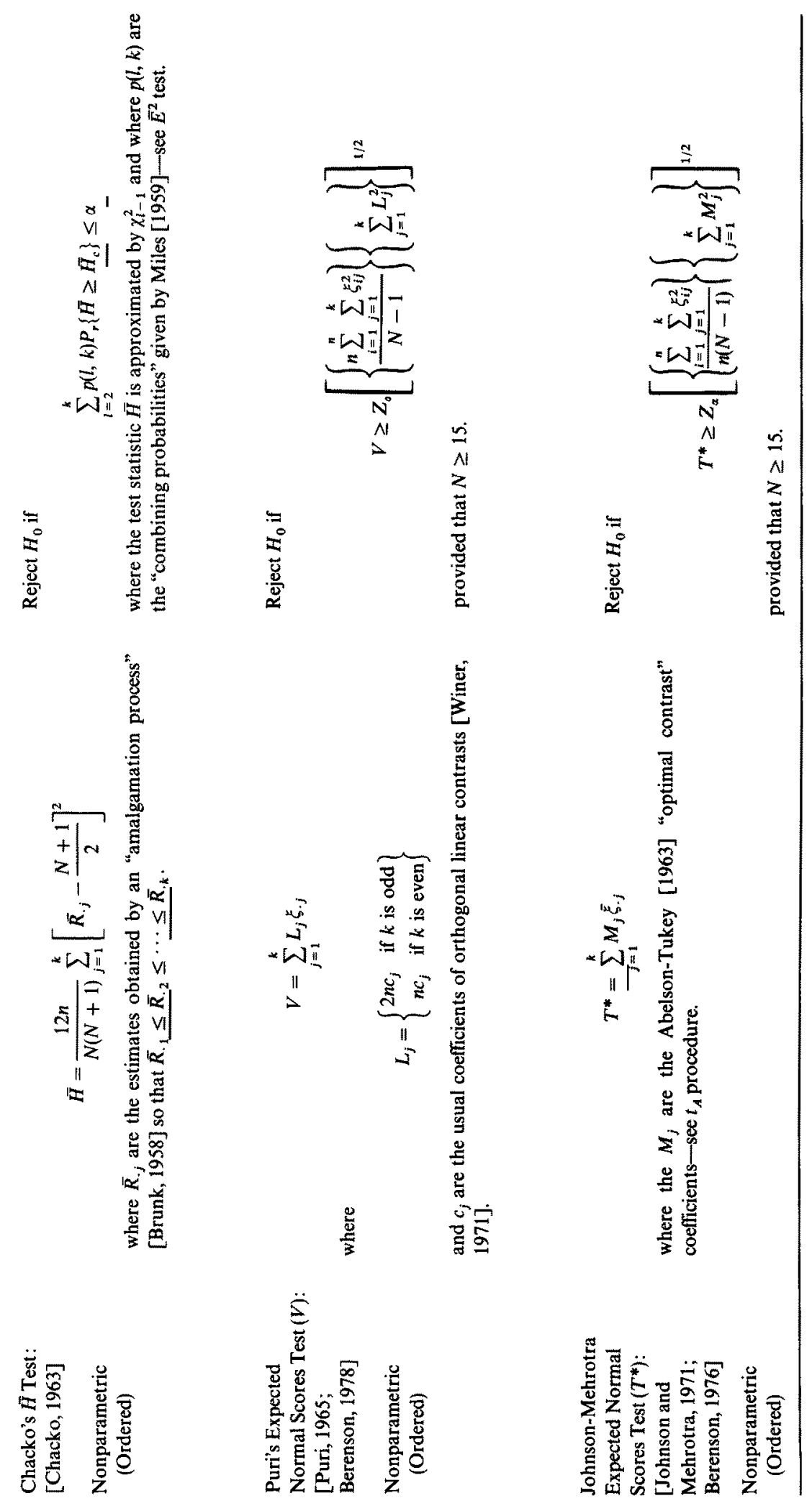